\title{
Role of non-drainage of subretinal fluid in re-operation for retinal detachment
}

P. K. LEAVER, A. H. CHIGNELL, L. G. FISON, J. R. PYNE, AND

S. H. SAUNDERS

From the Retinal Unit, Moorfields Eye Hospital, London

The technique of retinal detachment surgery without drainage of subretinal fluid (SRF), introduced by Custodis and developed by Lincoff, has been shown to be appropriate in the management of some cases of retinal detachment (Custodis, 1953; Lincoff, Baras, and McLean, 1965; Lincoff and Kreissig, 1972; Scott, 1970; Chignell, 1974). However, the extent to which this technique can be used still remains a controversial question.

The role of non-drainage in the more complicated cases and, in particular, in the eye which has previously undergone surgery for retinal detachment has not been fully established. Because the management of these cases provides a stern test of the effect of the surgical techniques used, it was decided to undertake a study of the re-operations in cases of retinal detachment done in the Retinal Unit at Moorfields during a period of 4 years in order to assess the role played by this technique.

The term re-operation was taken to mean further surgery in any patient with retinal detachment who had previously undergone a scleral buckling procedure, who was re-operated upon in the Retinal Unit at Moorfields during the period January 1970 to September 1973. The number or nature of the previous operations and the place or places where these were carried out were not taken into account. The series therefore includes patients who had undergone several previous procedures, sometimes in other hospitals, and also cases in which a wide variety of different surgical methods had previously been employed.

A successful result was taken to mean one in which complete anatomical re-attachment of the retina was achieved with a minimum period of follow-up of 6 months.

\section{Material and methods}

Although the surgery in this series of cases was performed by several different surgeons, the materials used and the methods employed were the same in all the cases.

Address for reprints: P. K. Leaver, FRCS, Retinal Unit, Moorfields Eye Hospital, City Road, London EC1V 2PD
Full-thickness scleral buckling with externally placed silastic sponges or silicone-rubber bands was invariably used and cryotherapy was applied through full-thickness sclera. 194 cases underwent re-operation during the 4-year period, and of these 103 were successful after the first re-operation and a further 26 were successful after more than one re-operation, making a final success rate of 66 per cent. In 65 cases, successful re-attachment of the retina was never achieved (Table I).

Table I Results in 194 cases

Successful after one re-operation Finally successful cases

Complete failures

Table II shows that in exactly one-third of the cases in this series, SRF was not drained and in two-thirds it was drained.

Table II $\quad$ 1970-1973

Number of re-operations

Number of cases drained

Number of cases not drained

194

$130(67 \%)$

$64(33 \%)$

\section{Results}

The figures set out in Table III suggest that reoperation without drainage of subretinal fluid is a more successful technique than that with drainage. However, this impression must be qualified when consideration is given to the type of case for which

Table III Results

\begin{tabular}{lll}
\hline Result & Drained (I30) & Not drained (64) \\
\cline { 3 - 4 } & & \\
Success & $70(54 \%)$ & $51(80 \%)$ \\
Failure & $60(46 \%)$ & 13 $(20 \%)$ \\
\hline
\end{tabular}


each method was chosen. Clearly those cases for which the non-drainage method was preferred carried a different prognosis from the outset to those which were managed by drainage of SRF. It was therefore decided to examine the failures which occurred after using the two methods to help to clarify the reasons for choosing which method to use in any particular case.

There were 13 failures among those cases in which SRF was not drained (Table IV). It was the purpose of this study to determine in which of these cases this method of treatment should not have been chosen.

\section{Table IV 13 failures after non-drainage}

Massive preretinal retraction

No retinal break found

Failure to close break

No definite cause found

In six cases progressive fibrosis eventually led to massive preretinal retraction (MPR), but as can be seen in Table VI in five of these vitreous and/or preretinal fibrosis was present before surgery. When vitreous or preretinal fibrosis in the region of the retinal break is present preoperatively, the immobility of the retina makes it difficult for spontaneous apposition of the break to the scleral buckle to occur. It is necessary in these circumstances to drain the SRF (Scott, 1972). In five of these failures, therefore, it would have been wiser to have drained SRF in order to ensure that the retinal break was closed at the time of surgery. In a further three cases no retinal break was found before or at the time of surgery and no strong presumptive evidence of the position of the break was present (Lincoff and Gieser, 1971). Local scleral buckling procedures without drainage of SRF were nevertheless done in these cases, when it would have been wiser to have encircled these eyes and drained the SRF. Thus eight of the 13 failures after non-drainage might have been avoided if the choice of operation had been different. It was in fact possible to re-attach the retina in eight cases by means of a subsequent drainage procedure.

In two cases the placing of the silastic sponge at surgery was inaccurate and in another two cases no adequate explanation was found to account for failure. Thus failure would have occurred in only five cases managed without drainage of SRF, if the choice of technique had been correct.

Sixty failures occurred after drainage of SRF and in all of these failure was complete. As can be seen in Table V, the majority of these were due to MPR. In three cases anterior segment necrosis occurred after the use of an encircling band. In three cases no retinal break was ever found and the cause of failure was uncertain. In a further five cases more surgery
Table V 60 failures after drainage

Massive preretinal retraction $\quad 46$

Anterior segment necrosis $\quad 3$

No retinal break found 3

No further surgery advised $\quad 5$

No definite cause found

was not advised for medical or other reasons and in three cases no adequate cause for failure was found.

In Table VI the cases of massive preretinal retraction are analysed to show whether this complication was actually caused by the surgery or was present before re-operation was undertaken. The figures show that, in the drainage group, 28 out of the 46 cases of MPR developed this after surgery (6I per cent), whereas in those that were not drained, only one out of the six did so.

Table VI 52 cases of massive preretinal retraction

\begin{tabular}{|c|c|c|}
\hline Preoperative fibrosis & Drained & Not drained \\
\hline $\begin{array}{l}\text { Present } \\
\text { Absent }\end{array}$ & $\begin{array}{l}18 \\
28\end{array}$ & $\begin{array}{l}5 \\
I\end{array}$ \\
\hline Total & 46 & 6 \\
\hline
\end{tabular}

These results are in accord with the findings previously obtained in this Unit, when it was found that at least $3^{8}$ per cent of the cases of MPR had suffered serious complications at or after surgery and that most of these were as a result of the drainage of SRF, in particular choroidal haemorrhage (Chignell, Fison, Davies, Hartley, and Gundry, I973).

\section{Discussion}

In the more favourable cases of retinal detachment which are managed without drainage of SRF, some failures still occur. It was the purpose of this study of 194 re-operations to discover if these failures were attributable to the technique itself or to error in choosing when to use it. If it can be shown that the cause of failure in most cases was attributable to error in the choice of the technique used rather than to a fault in the technique itself, the number of failures could have been greatly reduced if the decision not to drain the SRF had always been the correct one.

The non-drainage technique may be expected to be as successful in the re-operation as it has already been shown to be in the primary case, provided that the cases in which it is used are suitable. It is upon the criteria which are used to decide whether to drain or not to drain that the value of each technique depends. It has been found in our Unit that the following 
criteria when carefully applied yield the best results from surgery without drainage:

(I) Knowledge of the position of the retinal break at or before surgery, either by direct observation or by strong presumptive evidence based on the distribution of the SRF.

(2) Mobility of the retina at least at the site of the retinal break so that the break, if not closed at operation, can settle on to the buckle subsequently.

(3) It must be possible, at the time of surgery, to localize the break(s) accurately in relation to the buckle so that when the SRF absorbs the break falls on the buckle.

(4) No factors are present which make a sudden rise in intraocular pressure undesirable, such as very recent cataract extraction or ipsilateral vascular perfusion problems.

Careful selection of cases according to these criteria should yield as good results in the re-operation as in the primary case. Analysis of the failures in this series of cases managed by the non-drainage technique shows that more than half of these could have been avoided if the correct operation had been chosen.

Having shown, previously, that complications of SRF drainage are a major contributory factor in the genesis of MPR and that MPR is the commonest cause of failure in the re-operation, it must be concluded that drainage should be avoided whenever possible.

The role of non-drainage in the re-operation is therefore the same as it is in the case which has undergone no previous surgery.

\section{Summary}

In a study of 194 re-operations for retinal detachment in which one-third of the cases were managed without drainage of subretinal fluid, it was found that a number of failures occurred after non-drainage. Analysis of these failures shows that more than half could have been avoided if the correct choice of cases suitable for management without drainage of subretinal fluid had been made.

It is felt that with careful attention to the criteria which are used to decide on the choice of surgical technique, the results obtained by the non-drainage method should be as good in the more complicated case as they have already been shown to be in the primary case.

Because the drainage of subretinal fluid carries with it a risk of surgical complications and these complications may contribute to the development of massive preretinal retraction, management of the re-operation should be carried out without drainage of subretinal fluid whenever possible.

\section{References}

Ghignell, A. H. (1974) Amer. 7. Ophthal., 77, I

- Fison, L. G., DAVIES, E. W. G., HARTLEY, R. E., and GUNDRY, M. F. (1973) Brit. 7. Ophthal., 57, 525

Custodis, E. (1953) Ber. dtsch. ophthal. Ges., 58, 102

LINCoff, H. A., BaRAs, I., and malean, J. (1965) Arch. Ophthal. (Chicago), 73, i6o and GIESER, R. (I97I) Ibid., 85, 565

- and Kreissig, I. (1972) Trans. Amer. Acad. Ophthal. Otolaryng., 76, I 22 I

scotT, J. D. (1970) Trans. ophthal. Soc. U.K., 90, 57

(1972) Ibid., 92, 35I 